Supporting Information

\title{
Bimetallic PdCu Nanoparticles for Electrocatalysis: multiphase or homogeneous Alloy?
}

\author{
Yuanzhe Cheng ${ }^{\ddagger}$ Jing Xue ${ }^{\ddagger}$, Min Yang, Hongliang Li and Peizhi Guo*
}

Institute of Materials for Energy and Environment, State Key Laboratory of Bio-fibers and Eco-textiles, College of Materials Science and Engineering, Qingdao University, Qingdao, 266071, P. R. China.
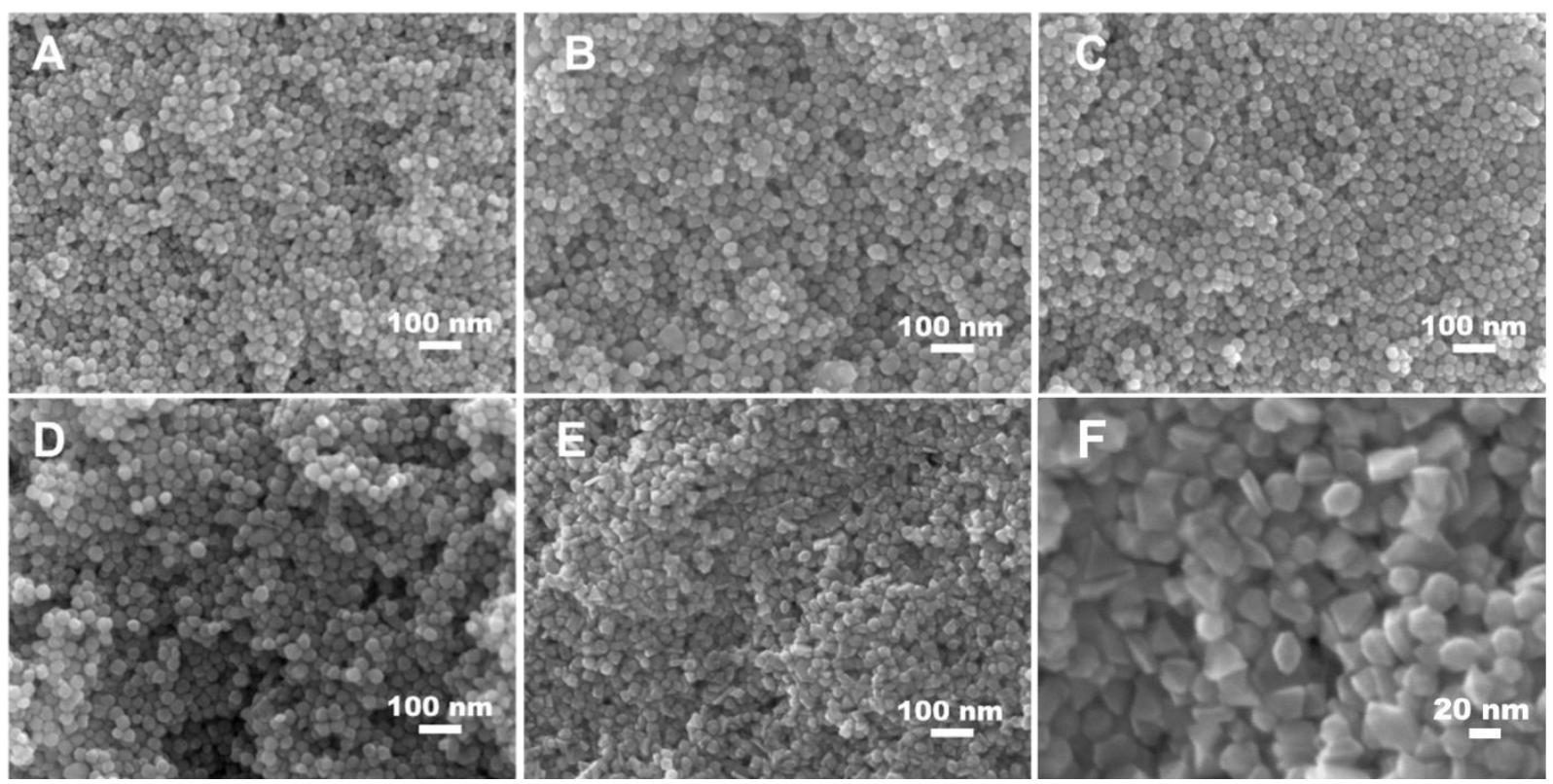

Figure S1. SEM images for $\mathrm{PdCu}-1$ (A), $\mathrm{PdCu}-2$ (B), $\mathrm{PdCu}-3$ (C), $\mathrm{PdCu}-4$ (D), $\mathrm{Pd}$ (E,

F) NPs. 

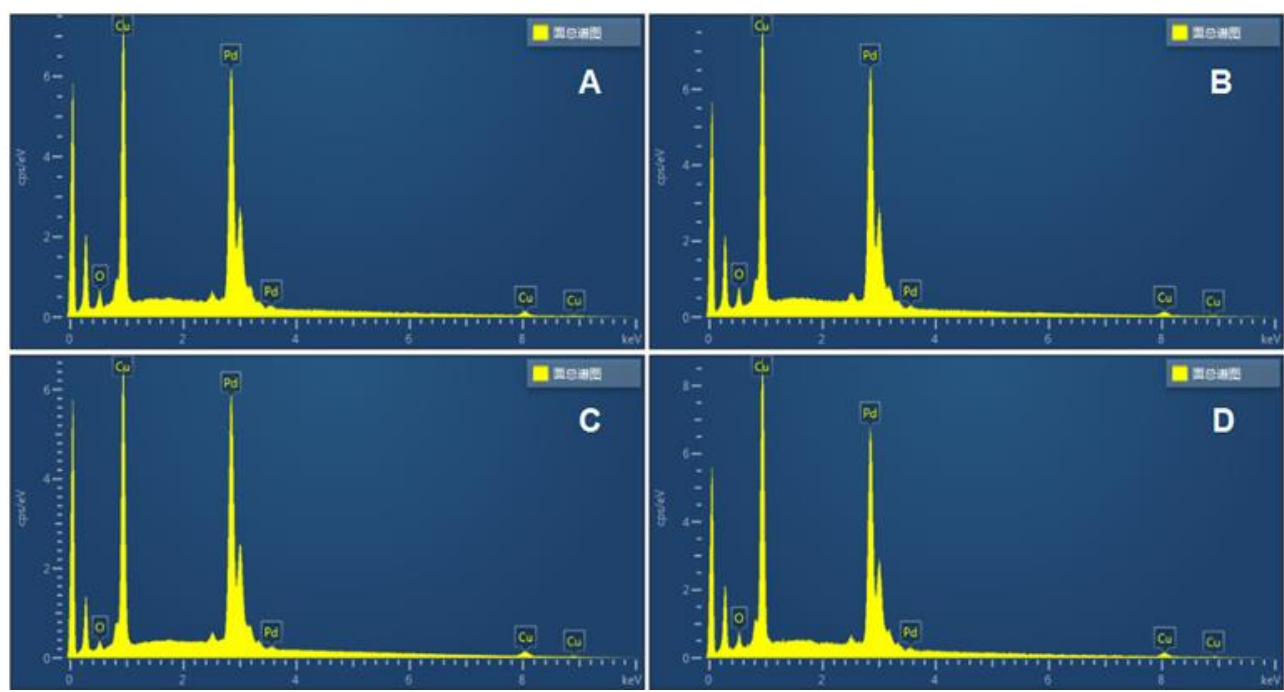

Figure S2. The EDS spectra of PdCu-1(A), $\mathrm{PdCu}-2$ (B), $\mathrm{PdCu}-3$ (C) and $\mathrm{PdCu}-4$ (D).

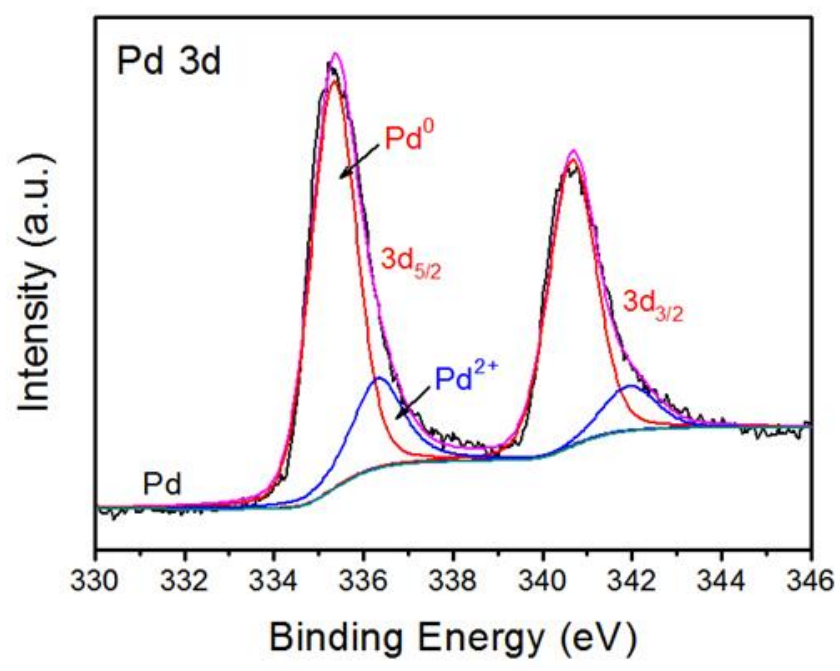

Figure S3. High-resolution XPS spectrum of Pd 3d for pure Pd NPs. 


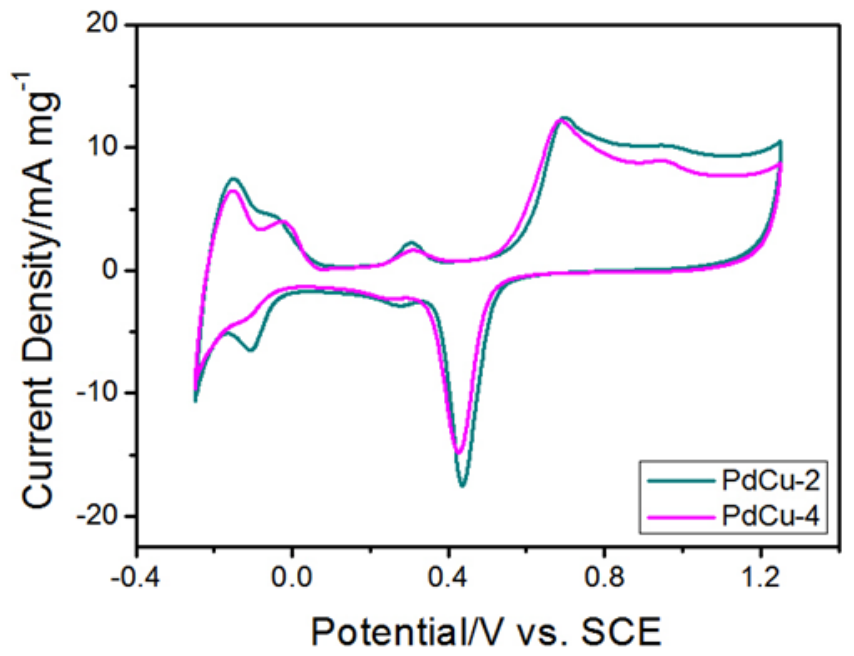

Figure S4. CVs of the PdCu-2 and $\mathrm{PdCu}-4$ modified electrodes in $0.5 \mathrm{M} \mathrm{H}_{2} \mathrm{SO}_{4}$ at a scanning rate of $20 \mathrm{mV} \mathrm{s}^{-1}$.
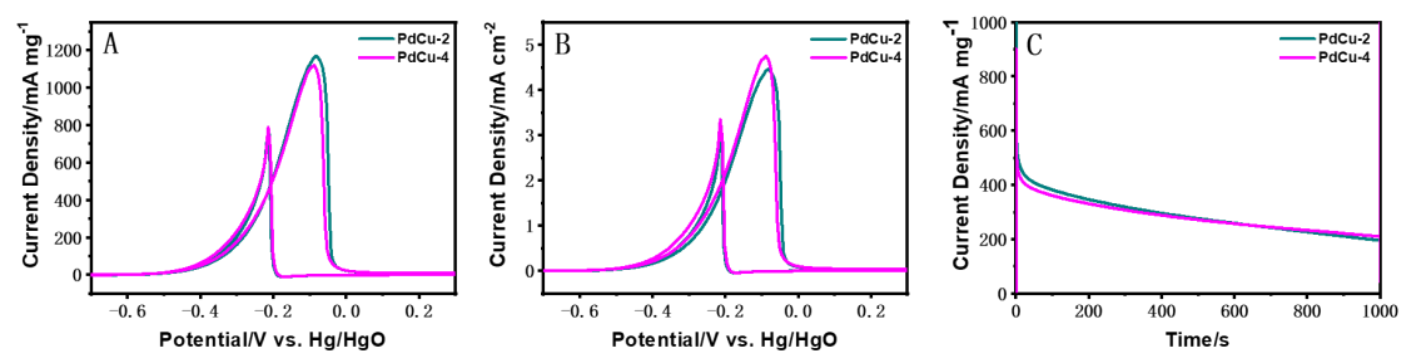

Figure S5. $\mathrm{CV}$ s of the $\mathrm{PdCu}-2$ and $\mathrm{PdCu}-4$ modified electrodes in $1 \mathrm{M} \mathrm{KOH} / 1 \mathrm{M}$ $\mathrm{C}_{2} \mathrm{H}_{5} \mathrm{OH}$ at $50 \mathrm{mV} \mathrm{s}^{-1}$ normalized by mass (A) and active surface area (B) as well as the correspongding chronoamperometric curves at $0.3 \mathrm{~V}(\mathrm{C})$.
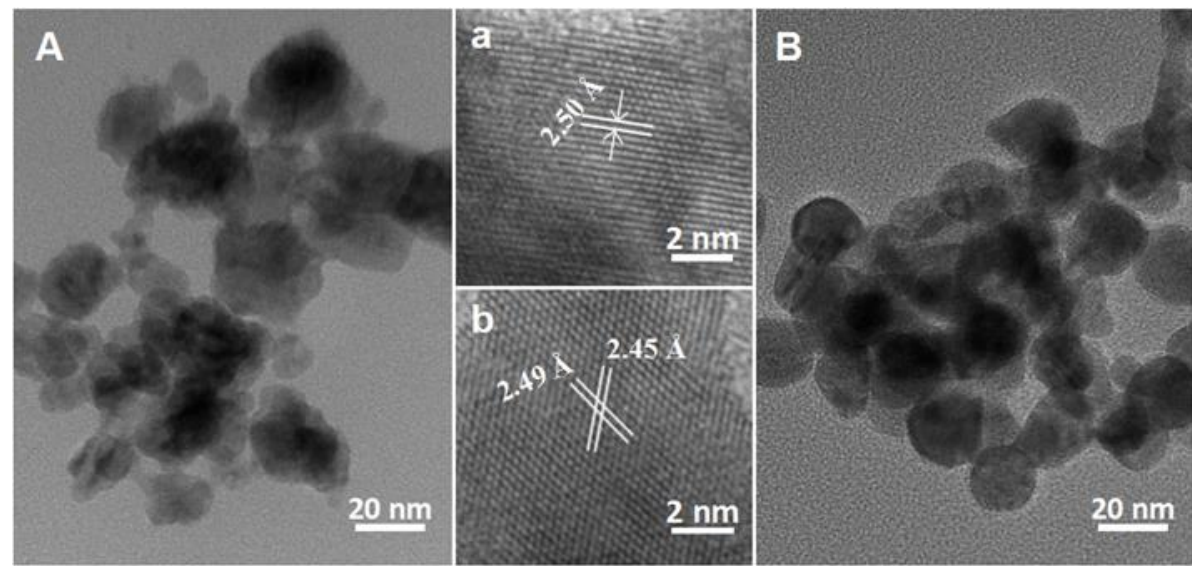
Figure S6. TEM (A, B) and $\operatorname{HRTEM}(\mathrm{a}, \mathrm{b})$ images of $\mathrm{PdCu}-1$ (A, a) and $\mathrm{PdCu}-3$ (B, b) after the 600 scanning cycles of ethanol oxidation.
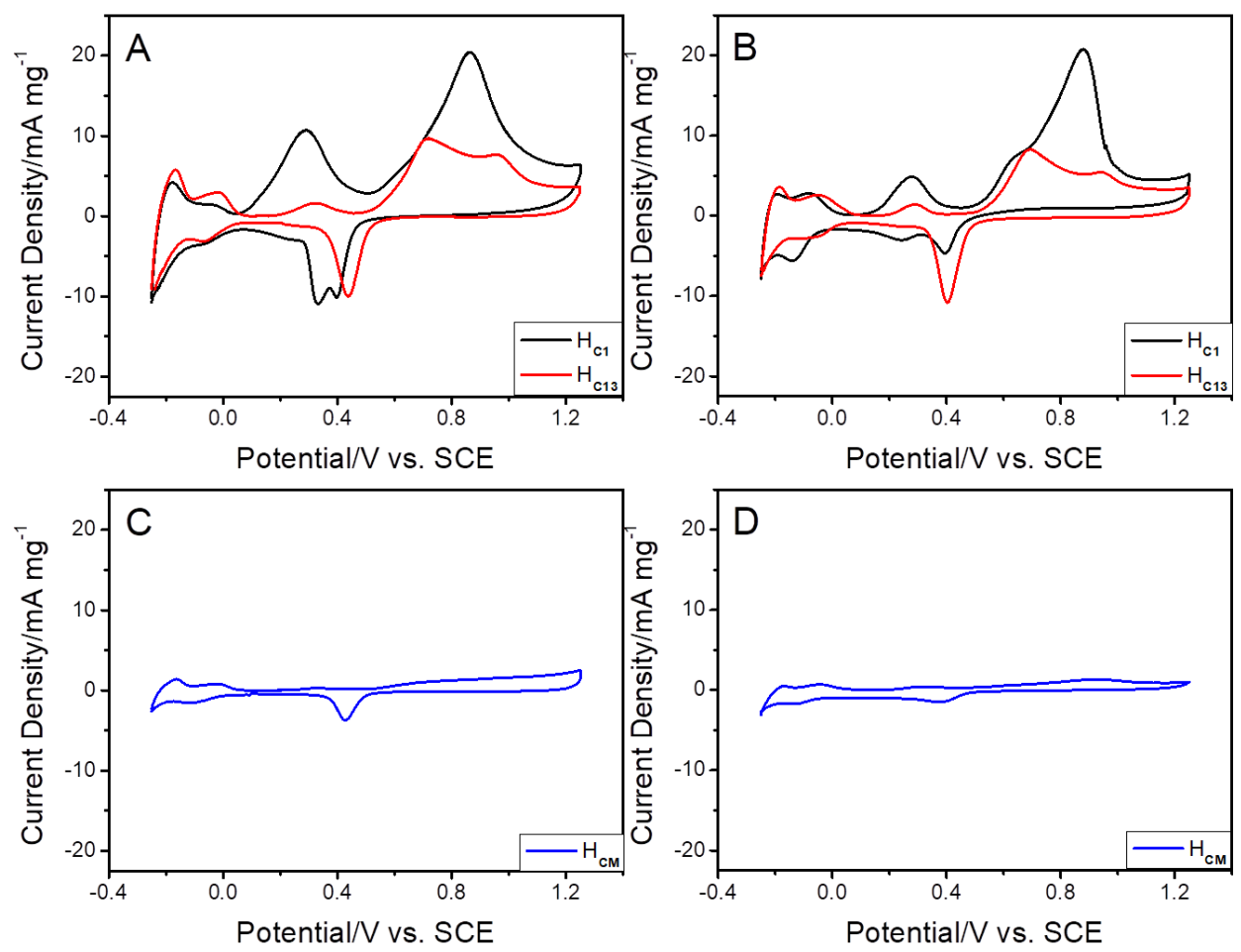

Figure S7. CVs of PdCu-1 (A, C) and PdCu-3 (B, D) NPs in $0.5 \mathrm{M} \mathrm{H}_{2} \mathrm{SO}_{4}$ at $20 \mathrm{mV} \mathrm{s}^{-}$ ${ }^{1}$ with different cycle numbers: $\mathrm{H}_{\mathrm{C} 1}\left(1_{\text {th }}\right.$ cycle), $\mathrm{H}_{\mathrm{C} 13}$ (13 $3_{\text {th }}$ cycle), $\mathrm{H}_{\mathrm{CM}}$ (with overmuch cycles until the disappearance of oxidation peak for $\mathrm{Cu}$ at $\sim 0.34 \mathrm{~V}$ ). 


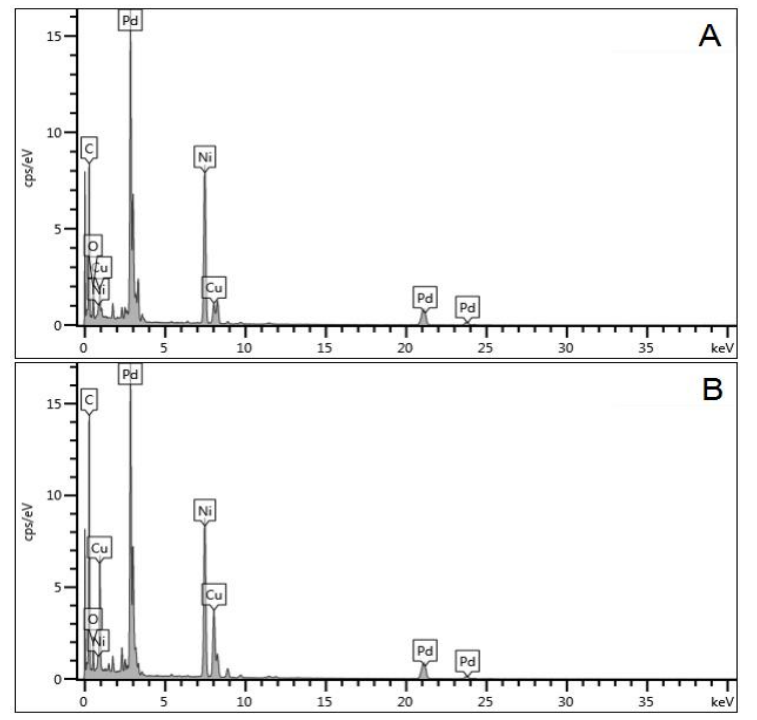

Figure S8. The EDX spectra of $\mathrm{PdCu}-\mathrm{S} 1$ (A) and $\mathrm{PdCu}-\mathrm{S} 3$ (B). 